\title{
Knowledge of cervical cancer risk factors among students at the Jan Kochanowski University in Kielce
}

\author{
Piotr Lewitowicz¹, Agata Horecka-Lewitowicz², Olga Adamczyk-Gruszka³ \\ ${ }^{1}$ Department of Pathology, Jan Kochanowski University, Kielce, Poland \\ Head of the Department: Prof. Anna Nasierowka-Guttmejer \\ 2 Public Health Institute, Jan Kochanowski University, Kielce, Poland \\ Head of the Department: Prof. JKU Monika Springer \\ ${ }^{3}$ Department of Gynaecology, Jan Kochanowski University, Kielce, Poland \\ Head of the Department: Prof. Mariusz Bidziński
}

Studia Medyczne 2013; 29 (3): 255-259

Key words: human papilloma virus, cervical cancer risk factors, cervical cancer prevention, cancer education.

\begin{abstract}
Introduction: Cervical cancer is the third most common malignant tumour in women. As far as we know today, the main cause of cervical cancer is human papilloma virus (HPV) infection with high grade oncogenic HPV genotypes, as well as co-occurrence of other factors predisposing women to cervical cancer. According to the WHO, the factors include smoking, multiple sexual partners, low socioeconomic status, herpes simplex virus (HSV) co-infection, human immunodeficiency virus infection, and antioxidant and vitamin insufficiency in the diet.

Aim of the research: To assess the knowledge of cervical cancer among young women.

Material and methods: The survey was carried out in 2010-2012 in a group of 149 female students at the age of $20 \pm 1$ at the Jan Kochanowski Memorial University, Kielce prior to gynaecology, pathology and oncology classes. The questionnaire survey included closed multiple choice questions. The statistical analyais was conducted by means of PQStat ver. 1.4.4 software using ANOVA and Fisher tests.

Results and conclusions: The obtained results show that the $94 \%$ of the surveyed people are familiar with the impact of HPV infection, but knowledge of accessory risk factors of cervical cancer is at low level. The study revealed that smoking is regarded as another risk factor by $13 \%$ of the surveyed people, HSV infection by $9 \%$, multiple sex partners by $21 \%$, and low hygiene level by $25 \%$. Our examination revealed differences regarding the knowledge and available information sources by the respondents' place of residence. Knowledge level of cervical cancer development depends on the place of residence and reaches the highest level in towns with over 20,000 inhabitants. The main source of information on cervical cancer risk factors is Internet and peer opinions.
\end{abstract}

\section{Introduction}

Cervical cancer is the third most frequent malignant tumour in women. As far as we know today, the main cause of cervical cancer is human papilloma virus (HPV) infection, in particular with high grade oncogenic HPV genotypes, such as HPV-16 and HPV18 , as well as co-occurrence of other factors predisposing women to cancer [1-4]. According to the WHO, the factors include smoking, multiple sexual partners, low socioeconomic status, herpes simplex virus (HSV) co-infection, human immunodeficiency virus (HIV) infection, and antioxidant and vitamin insufficiency in the diet. In most countries, exfoliative cytology has been applied as the primary screening method since the 1950s. Cytological smear was first analysed using Papanicolaou testing, but nowadays it is assessed in accordance with the Bethesda system. Cytology on liquid basis (LBC) is another screening test. Vaccination against HPV is more and more widely used as the primary preventive method against cervical cancer.
The introduction of new HPV infection molecular diagnostic methods is a new trend in cervical cancer diagnosis.

Screening methods and policies providing information on cervical cancer prevention vary worldwide. Since the efficiency of the programmes differs in many countries, although similar methods are used, the assumption can be made that the reason for poor cervical cancer diagnosis in most countries is women's poor knowledge of carcinogenic and cancer risk factors [5-9]. The statistics in Poland during the period 2000-2009 show a decrease in the total number of cancer diagnoses in 3100 cases out of 3800 annually. There is a noticeable drop in the incidence rate among women aged $30-50$, but no decrease or an increase in the incidence proportion among elderly women [10]. The changes may be associated with the campaign agitating for screening tests, higher awareness among women aged 30-50, and inadequate screening care and information programmes among women in their fifties. 


\section{Aim of the research}

The purpose of the study is to assess the knowledge of cervical cancer risk factors among young women as well as to analyse different knowledge levels and educational methods to learn by place of residence.

\section{Material and methods}

The study was carried out during the period 2010 2012 in a group of 149 female students aged $20 \pm 1$ at the Department of Surgery and Surgical Nursing with Scientific Laboratory at the Jan Kochanowski Memorial University, Kielce, prior to gynaecology, pathology and oncology classes.

\section{Statistical analysis}

The survey included closed multiple choice questions. The statistical analysis was conducted by means of PQStat ver. 1.4.4 software using ANOVA and Fisher tests.

\section{Results}

Table 1 shows the division of the respondents by their place of residence. The statistical analysis of the surveyed groups does not indicate significant statis-

Table 1. The distribution of the respondents by their place of residence

\begin{tabular}{|lccc|}
\hline $\begin{array}{l}\text { Residence } \\
\text { (inhabitants) }\end{array}$ & Number & Percentage & $\begin{array}{c}\text { Value of } \\
\boldsymbol{p}\end{array}$ \\
Village & 78 & 28 & \\
Town up to 20,000 & 67 & 24 & 0.21 \\
Town 20-100,000 & 75 & 27 & \\
City over 100,000 & 59 & 21 & \\
\hline
\end{tabular}

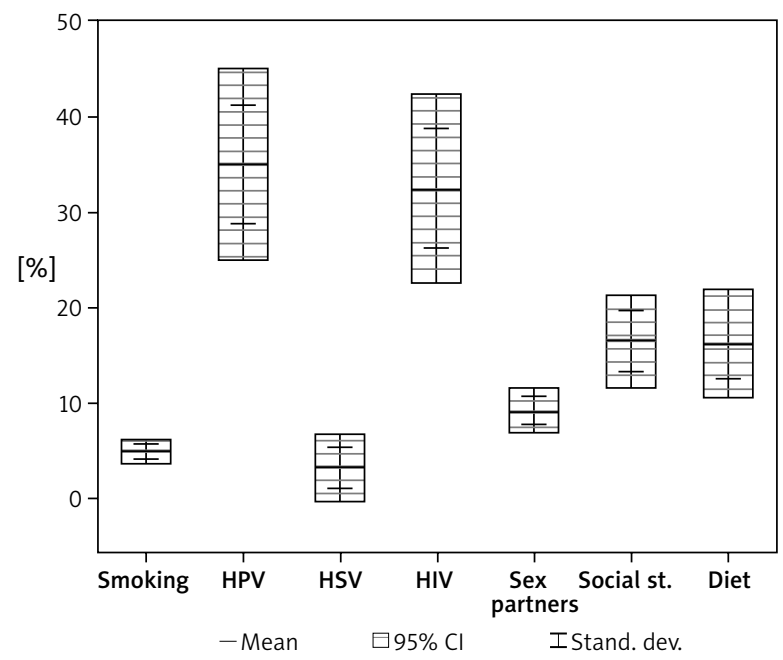

Figure 1. Graphic representation of Table 1 tically differences between the groups as far as their residence is concerned ( $p=0.21$ ) (Figure 1).

Tables 2 and 3 show the percentage of the obtained correct answers not determined and determined by place of residence. The knowledge levels regarding the role of HPV infection ( $p=0.015)$ and HIV infection ( $p=0.026)$ are statistically significantly different from the knowledge level regarding other HIV infection risk factors.

Statistically significant differences were revealed between the female respondents' place of residence and their knowledge level regarding the cervical cancer risk factors. Statistically significantly different knowledge levels regarding particular risk factors by place of residence were also observed $(p<0.0001)$.

The assessment of the knowledge about the link between smoking and cervical cancer revealed that $13 \%$ of the surveyed women know the impact of smoking on cervical cancer. The remaining $87 \%$ think that smoking is connected with the development of respiratory cancer and cardiovascular diseases. As far as the question about a potential influence of HPV infection on cervical cancer development is concerned, only $6 \%$ of the surveyed students did not know this dependence. Ninety-one percent of the surveyed women did not know the relationship between HSV infection and a higher risk of cervical cancer development. However, the respondents indicated the association between HSV infection and the occurrence of labial herpes as well as decreased immunity. Eighty-seven percent of the women stated that HIV infection affects cancer development but only $10 \%$ knew the association between opportunistic infections and cervical cancer development, and they recognized HIV infection as a direct-acting carcinogenic factor. The assessment of knowledge about the association between the number of sexual partners and the risk of cancer development revealed that only $21 \%$ of the surveyed women were aware of such a risk. Seventy-nine percent indicated (as a response

Table 2. The total number of answers indicating the recognized cervical cancer risk factor

\begin{tabular}{|lc|}
\hline Risk factors & $\begin{array}{c}\text { Percent of answers } \\
\text { indicating possible } \\
\text { relationship to cancer }\end{array}$ \\
Smoking & 13 \\
HPV infection & 94 \\
HSV infection & 9 \\
HIV infection & 87 \\
Number of sexual partners & 21 \\
Poor hygiene level & 25 \\
Socioeconomic status & 46 \\
Types of diet & 44 \\
\hline
\end{tabular}


Table 3. Answers variability by place of residence

\begin{tabular}{|c|c|c|c|c|c|c|}
\hline Risk factors & Village & $\begin{array}{l}\text { Town up to } \\
20,000\end{array}$ & $\begin{array}{c}\text { Town } 20,000- \\
100,000\end{array}$ & $\begin{array}{l}\text { City over } \\
100,000\end{array}$ & $\begin{array}{l}\text { Mean } \\
\text { (STD) }\end{array}$ & $\begin{array}{c}\text { Value of } p \\
\text { ANOVA/Fisher } \\
\text { test }\end{array}$ \\
\hline Smoking & 5 & 4 & 6 & 5 & $5(0.81)$ & \multirow{7}{*}{$<0.0001$} \\
\hline HPV & 30 & 37 & 43 & 30 & $34(6.27)$ & \\
\hline HSV & 2 & 1 & 4 & 6 & $3.25(2.21)$ & \\
\hline HIV & 25 & 31 & 34 & 40 & $32(6.24)$ & \\
\hline $\begin{array}{l}\text { Number of sexual } \\
\text { partners }\end{array}$ & 10 & 11 & 10 & 6 & $9.25(1.5)$ & \\
\hline $\begin{array}{l}\text { Socioeconomic } \\
\text { status }\end{array}$ & 15 & 13 & 18 & 20 & $16.5(3.1)$ & \\
\hline Diet & 21 & 17 & 14 & 13 & $16.25(3.5)$ & \\
\hline
\end{tabular}

Table 4. The information sources assessment by place of residence

\begin{tabular}{|c|c|c|c|c|c|c|}
\hline $\begin{array}{l}\text { Sources of the } \\
\text { information }\end{array}$ & $\begin{array}{c}\text { Village } \\
(\%)\end{array}$ & $\begin{array}{c}\text { Town up to } \\
20,000 \\
(\%)\end{array}$ & $\begin{array}{c}\text { Town } \\
20,000- \\
100,000(\%)\end{array}$ & $\begin{array}{c}\text { City over } \\
100,000(\%)\end{array}$ & Mean (STD) & $\begin{array}{l}\text { Value of } p \\
\text { ANOVA/ } \\
\text { Fisher test }\end{array}$ \\
\hline School & 7 & 4 & 5 & 10 & $6(2.5)$ & 0.020 \\
\hline Colleagues & 25 & 20 & 20 & 30 & $22.5(4.7)$ & 0.002 \\
\hline Web & 50 & 54 & 64 & 70 & $59(9.9)$ & 0.001 \\
\hline Parents & 3 & 10 & 12 & 13 & $11(4.5)$ & 0.032 \\
\hline Television & 4 & 0 & 0 & 1 & $0.5(1.9)$ & 0.8 \\
\hline Newspapers & 1 & 3 & 1 & 5 & $2(1.9)$ & 0.21 \\
\hline
\end{tabular}

to this question) the possibility of inflammation and venereal diseases without any correlation with HPV and other infections. The question on the impact of poor hygiene level on cervical cancer revealed that $11 \%$ knew the possible correlation between cervical cancer and chronic infections. Eighty-nine percent of the surveyed students think that poor hygiene level is only the cause of inflammation and does not result in cancer development. The material conditions analysis divided the students into two almost equally numbered groups. Half of them think that cancer is associated with material conditions, but they cannot explain such a correlation. Thirty percent are aware of the correlation between poor material conditions, education, cancer awareness as well as improper diet. The influence of diet on cervical cancer development is indicated in $14 \%$ of the answers. Eighty-six percent consider diet and its effects as the reason for digestive system diseases.

Terms such as antioxidants, trace elements and vitamins are commonly known (98\% affirmative answers). However, the knowledge about their role in cancer prevention is poor ( $12 \%$ affirmative answers).

Table 4 presents the assessment of sources providing information on carcinogenic factors by place of residence (Figure 2). Significant differences were observed as regards gaining knowledge by place of residence.

\section{Discussion}

The analysis of the obtained results indicates high levels of knowledge about one of the most important

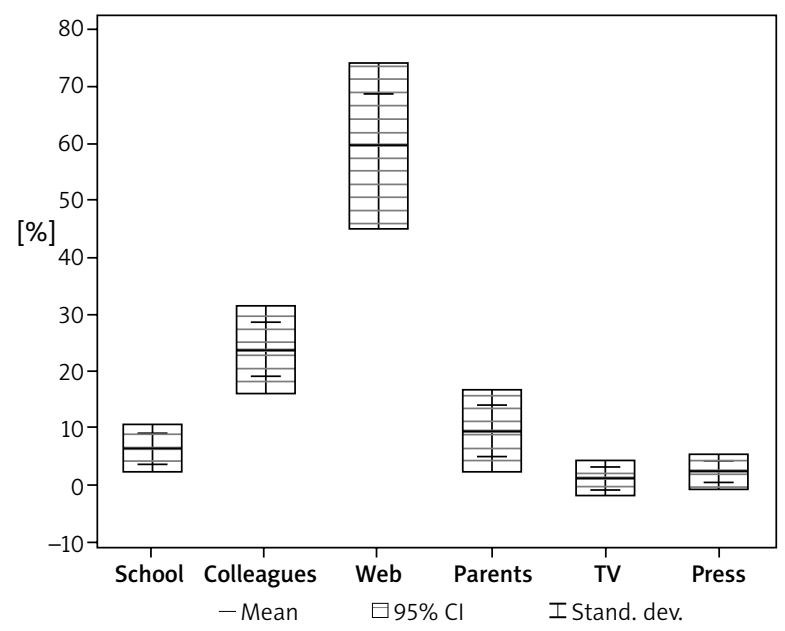

Figure 2. Graphic representation of Table 4 
aetiological cervical cancer factors, i.e. HPV infection. The knowledge among young women about the impact of lifestyle and virus co-infection on cervical cancer development is insufficient. As regards the knowledge level about the cancer risk factors, the study revealed differences between the communities in big cities, medium and small towns, and villages. As far as the information sources are concerned, there are also statistically significant differences. The predominance of Web and colleagues, as well as minor influence of schools, newspapers and television on cancer awareness and development of knowledge about potential carcinogenic factors are also observed. It should be noted that cancer is considered to be a unifactorial disease and there is no wider view of its potential multifactorial etiology.

Although the HPV infection impact on cervical cancer development is commonly known, in some countries and parts of the world the cancer incidence rate remains stable or is rising. Genetic heterogeneity and the spread of HPV virus make it difficult to promote effective and reliable prevention activities applying exfoliative cytology. The first routine screening test is performed at different ages in many countries, and it varies between the ages of 20-25. It seems adequate as far as cervical cancer prevention is concerned, but it should be taken into consideration that sexual initiation age is becoming lower, risky sexual behaviour is rising, and costs, including social, of excision for high grade squamous intraepithelial neoplasia (HGSIL) are getting higher. The examination of 940 healthy school children in India by Hussain et al. revealed asymptomatic HPV infection with genotypes 16 and 18 among 3\% of girls before sexual initiation, and infection with low-risk genotypes mainly type 6 [1] among $2 \%$ of boys. The examination of 435 female students conducted by Silva et al. showed that $11 \%$ of HPV infections were caused mainly by type 31, 16, 53 and 61. The HPV infection percentage increased to $16 \%$ during sexual activity, and there was a correlation with the number of sexual partners and the period of sexual activity [2].

Apart from the HPV infection analysis, most of the researchers studying carcinogenic factors consider another factor, i.e. poor access to healthcare, which is also associated with poor material conditions. In such groups, it is recommended to employ modified preventive systems based not only on exfoliative cytology, but also on simultaneous HPV tests using molecular biology techniques. Lazcano-Ponce et al. conducted DNA testing in 12,330 women aged 28-65 from poor Mexican regions. The research revealed high sensitivity for cervical intraepithelial neoplasia grade 2 (CIN2) detection and HPV prevalence was $9.8 \%$. The authors suggest routine HPV testing for women who are irregularly screened [3].
Smoking is considered as a risk factor of development of respiratory cancer and cardiovascular diseases. It can be assumed that the knowledge about other smoking dependant cancers including cervical cancer is poor. The present study demonstrated that only $13 \%$ of young women were familiar with the impact of smoking. Underwood et al. assessed cervical cancer incidence rate in the USA during the period 1992-2008 and observed that female smokers with cervical cancer were twice more prone to coexistent smoking-dependent cancers [4].

Screening programmes vary in many countries and depend on healthcare expenditure. In Poland, the programme provides free cytology screening tests for women aged 25-59 every 3 years. Despite the invitations for the test, the participation rate is about $25 \%$ [5]. Such poor attendance can be improved by employing other methods to inform women and to persuade them to take part in tests. Knapp et al., study demonstrated that $21^{\text {st }}$ century media such as radio, television and the internet are excellent communication tools and should be employed in screening [6]. The reports from 2010 in the USA indicated $83 \%$ of cervix screening tests, but the target result of $93 \%$ was low due to poor participation of Asian and black people [7]. Kulasingam et al. suggest that colposcopy should be employed more often in testing and women should be screened after they are 21 years old [8]. Cervical screening programmes in the UK are based on LBC and high grade HPV molecular testing. The authors of the programme observed dynamic changes in the number of the women vaccinated against HPV, as well as cultural and social changes imposing alternation of the existing patterns $[9,10]$. Similar conclusions regarding the changes in screening patterns were made by Norwegian scientific researchers. On cost-effectiveness analysis, they concluded that the Norwegian programme which is solely based on exfoliative cytology is less effective and more expensive than the programme based on HPV testing and HPV vaccination. According to the authors, the prevention programme should depend on several factors, mainly age, female patient's history and vaccines [11].

A lot of countries have implemented mandatory HPV vaccination for girls aged 11-13 and it seems that the problem of cervical cancer could be solved within the next few decades. However, it is just a partial solution, because a policy providing information on lifestyle and other risk factors should be introduced at the same time. The study made by Donati et al. demonstrate that the knowledge of cervical cancer prevention is sufficient only among female health service workers, whereas other women do not know the risk factors [12]. Papa et al. assessed the role of education in women's knowledge and believe that education considerably facilitates understanding of screening testing, test results, further management 
and regular screening [13]. Such a low cancer education level, which was observed in the present study, was assessed by other researchers as well. Klug et al., who surveyed 1500 women between the ages 25 and 75 , indicated that only $3 \%$ of the women have basic knowledge of the carcinogenic impact of HPV infection and the authors suggest more education on risk factors of the most common diseases [14]. Similar results showing poor knowledge of cervical cancer were obtained in a group of 1054 Estonian women by Kivistik et al. [15].

\section{Conclusions}

After the statistical analysis of the results, the following conclusions can be drawn: 1) knowledge level of the association between HPV infection and the risk of cervical cancer is high in the surveyed group; 2) awareness of other cervical cancer risk factors than $\mathrm{HPV}$ infection among the surveyed women is poor; 3) knowledge level of cervical cancer development depends on the place of residence and reaches the highest level in towns with over 20,000 inhabitants; 4) the main sources of information on cervical cancer risk factors are the Web and colleagues' opinions.

It can be concluded that the knowledge of the primary cervical cancer risk factor, i.e. HPV infection, among young women is reasonably good. The knowledge of other cervical cancer risk factors is poor. It can be assumed that the secondary school syllabus should cover basic issues regarding the role and significance of common disease risk factors, as well as cancer risk factors. The obtained results and the respondents choice of the internet as the main source of information show that available media such as the internet, radio, TV and newspapers should be employed as the main tools in the implementation of the policy providing information on cancer prevention programmes. An assumption can be made that the information on cancer prevention knowledge could be used in the development of modern screening programmes which could be organized by population age, awareness level and material conditions. Such a solution could facilitate, in the future, the improvement of screening and economic effectiveness of the prevention programmes regarding the diagnosis of cervical cancer and other tumours.

\section{References}

1. Hussain S, Bharadwaj M, Nasare V, et al. Human papillomavirus infection among young adolescents in India: impact of vaccination. J Med Virol 2012; 84: 298-305.

2. Silva J, Ribeiro J, Sousa H, et al. Oncogenic HPV types infection in adolescents and university women from North Portugal: from self-sampling to cancer prevention. J Oncol 2011; 2011: 953469

3. Lazcano-Ponce E, Lorincz AT, Cruz-Valdez, et al. Self-collection of vaginal specimens for human papillomavirus testing in cervical cancer prevention (MARCH): a community-based randomised controlled trial. Lancet 2011; 378: 1868-1873.

4. Underwood JM, Rim SH, Fairley TL, et al. Cervical cancer survivors at increased risk of subsequent tobacco-related malignancies, United States 1992-2008. Cancer Causes Control 2012, 23: 1009-1016.

5. Spaczyński M, Karowicz-Bilinska A, Rokita W, et al. Attendance rate in the Polish Cervical Cancer Screening Program in the years 2007-2009 [Polish]. Ginekol Pol 2010; 81: 655-663.

6. Knapp P, Zbroch T, Knapp P. The use of interactive medical data transfer to increase effectiveness of a mass screening program. Ginekol Pol 2004; 75: 896-903.

7. Centers for Disease Control and Prevention (CDC). Cancer screening - United States, 2010. MMWR Morb Mortal Wkly Rep 2012; 61: 41-45.

8. Kulasingam SL, Havrilesky L, Ghebre R, et al. Screening for Cervical Cancer: A Decision Analysis for the U.S. Preventive Services Task Force [Internet]. Rockville (MD): Agency for Healthcare Research and Quality (US); 2011.

9. Albrow R, Kitchener H, Gupta N, et al. Cervical screening in England: the past, present, and future. Cancer Cytopathol 2012; 120: 87-96.

10. National Comprehensive Cancer Network. Cancer Epidemiology and Prevention Department at Cancer Centre and Oncology Institute in Warsaw, Poland.

11. Burger EA, Ortendahl JD, Sy S, et al. Cost-effectiveness of cervical cancer screening with primary human papillomavirus testing in Norway. Br J Cancer 2012; 106: 1571-1578.

12. Donati S, Giambi C, Declich S, et al. Knowledge, attitude and practice in primary and secondary cervical cancer prevention among young adult Italian women. Vaccine 2012; 30: 2075-2082.

13. Papa D, Moore Simas TA, Reynolds M, et al. Assessing the role of education in women's knowledge and acceptance of adjunct high-risk human Papillomavirus testing for cervical cancer screening. J Low Genit Tract Dis 2009; 13: 66-71.

14. Klug SJ, Hetzer M, Blettner M. Screening for breast and cervical cancer in a large German city: participation, motivation and knowledge of risk factors. Eur J Public Health 2005; 15: 70-77.

15. Kivistik A, Lang K, Baili P, et al. Women's knowledge about cervical cancer risk factors, screening, and reasons for non-participation in cervical cancer screening programme in Estonia. BMC Womens Health 2011; 11: 43.

\section{Address for correspondence:}

Piotr Lewitowicz

Department of Pathology

Institute of Nursing and Obstetrics

Faculty of Health Sciences

Jan Kochanowski University

al. IX Wieków Kielce 19, 25-317 Kielce, Poland

Phone: +48 4134969 01/09

Fax: +48 413496916

E-mail: lewitowicz@onet.eu 